\title{
Response of two Arabidopsis ecotypes Columbia-0 and Dijon-G to necrotrophic and biotrophic pathogens
}

\author{
Y.H. LEE ${ }^{1+}$, Y.J. KIM ${ }^{1}$, J.Y. MOON ${ }^{2}$, H.J. KIM ${ }^{1}$, J.M. PARK ${ }^{2}$, I.S. HWANG ${ }^{3}$, and J.K. HONG ${ }^{1 *}$ \\ Department of Horticultural Science, Gyeongnam National University of Science and Technology, \\ Jinju 52725, Republic of Korea ${ }^{1}$ \\ Green Bio Research Center, Division of Biosystems Research, Korea Research Institute of Bioscience \\ and Biotechnology, Daejeon 34141, Republic of Korea ${ }^{2}$ \\ Department of Horticultural Biotechnology, Kyung Hee University, Yongin 17104, Republic of Korea ${ }^{3}$
}

\begin{abstract}
Arabidopsis thaliana L. ecotype Dijon-G (Di-G) showed a different symptom development during pathogenesis compared to ecotype Columbia-0 (Col-0). Previously, it has been shown that Di-G has a higher susceptibility to necrotrophic fungus Alternaria brassicicola than Col-0. In this study, Di-G showed enhanced disease susceptibility to necrotrophic fungi Botrytis cinerea, Sclerotinia sclerotiorum, and Sclerotium rolfsii known to secrete oxalic acid (OA) as a pathogenicity factor. Treatment with 50 and 100 mM OA resulted in a more leaf tissue collapse in Di-G than in Col-0. The OA also upregulated expression of the salicylic acid (SA)-inducible pathogenesis-related gene $1(P R 1)$ and down-regulated expression of the jasmonic acid/ethylene-inducible defensin PDF1.2 gene in Di-G. By contrast, Di-G was resistant to hemibiotrophic fungus Colletotrichum higginsianum and biotrophic Turnip crinkle virus (TCV) infections. Application of $0.5 \mathrm{mM}$ SA resulted in a higher accumulation of endogenous SA and in a preferential expression of SA-responsive genes in Di-G. Salicylic acid accelerated OA-triggered plant cell death and attenuated PDF1.2 expression in Di-G. These results suggest that the enhanced susceptibility of Di-G to necrotrophic pathogen infections might be mediated by attenuated JA-ethylene defence signalling and/or heightened SA-related defence signalling. Interaction of SA-signalling with OA secretion might be also involved in the enhanced susceptibility of Di-G.
\end{abstract}

Additional key words: oxalic acid, pathogenesis-related gene $P R 1$, plant defensin gene PDF1.2, salicylic acid.

\section{Introduction}

Plants have established sophisticated resistance machineries to combat invading pathogens via modulating multiple defence signalling pathways. It has been widely known that activation of defence signalling in plants is highly dependent on a behaviour of pathogens. Pathogens initiating biotrophic and hemibiotrophic infection usually activate salicylic acid (SA)-dependent signalling pathways within host plants whereas necrotrophic pathogens trigger jasmonic acid (JA)/ethylene-dependent signalling pathways (Glazebrook 2005). In Arabidopsis, SAmediated defences are elicited by biotrophic [Erysiphe cruciferarum, Hyaloperonospora arabidopsidis (formerly Peronospora parasitica), Turnip crinkle virus (TCV)], and hemibiotrophic pathogens [Pseudomonas syringae pv. tomato (Pst)] whereas JA/ethylene-activated defences are triggered by necrotrophic fungi Alternaria brassicicola and Botrytis cinerea (Nawrath and Métraux 1999, ChandraShekara et al. 2004, Xiao et al. 2005, Leon-Reyes et al. 2010). These different defence signalling pathways can interact with each other synergistically or antagonistically during plant immunity activation (Pieterse et al. 2009). One highly enhanced defence signalling pathway in plants could mitigate other defence signalling pathways antagonistically. The antagonistic interactions of defence pathways have been evidenced by differential defence responses of an array of Arabidopsis mutants with altered SA- or JA/ethylene-defence signalling compared to wildtype (Spoel et al. 2007, Mang et al. 2009).

Submitted 2 May 2018, last revision 8 April 2019, accepted 6 May 2019.

Abbreviations: Col-0 - Columbia-0; CP - coat protein; Di-G - Dijon-G; EDS - enhanced disease susceptibility; JA - jasmonic acid; NPR - nonexpresser of PR genes; OA - oxalic acid; PAD - phytoalexin deficient ; PDF - plant defensin; PDA - potato dextrose agar; PR - pathogenesis-related gene; SA - salicylic acid; TCV - turnip crinkle virus.

Acknowledgements: This work was financially supported by the National Research Foundation of Korea, and the Ministry of Education,

Science, and Technology (grant No. NRF-2017R1D1A3B03034400). The first two authors contributed equally to this paper.

+ Present address: National Institute of Ecology, 1210 Geumgang-ro, Seocheon-gun, Choongnam 33657, Republic of Korea.

* Corresponding author; e-mail: jkhong@gntech.ac.kr 
A variety of Arabidopsis ecotypes originated from different natural habitats have shown diversity in physiological responsiveness to many endogenous and exogenous stimuli including flowering, tolerance to dehydration and freezing, ozone sensitivity, and disease resistance (Kover and Schaal 2002, Lempe et al. 2005, Hannah et al. 2006, Bouchabke et al. 2008, Brosché et al. 2010). Symptom development on infected leaves and/or pathogen proliferation within leaf tissue are important criteria to differentiate disease resistance of various Arabidopsis ecotypes inoculated by viruses (Cauliflower mosaic virus, Oilseed rape mosaic tobamovirus, Turnip mosaic potyvirus), bacterium Pst, and fungus Botrytis cinerea (Leisner and Howell 1992, Martín et al. 1999, 2007, Kover and Schaal 2002, Perchepied et al. 2006, Rowe and Kliebenstein 2008). Altered disease resistance may be due to enhancement or attenuation of one or more defence signalling pathways. It is also possible to screen disease resistant or susceptible Arabidopsis ecotypes based on defence-related gene expression in response to treatments with defence regulators such as SA and JA (Van Leeuwen et al. 2007, Matthes et al. 2008, Ahmad et al. 2011). In recent decades, disease resistance-associated Arabidopsis ecotypes have been valuable resources to dissect defence signalling pathways and discover novel defence-related genes and metabolites against pathogens with distinct lifestyles and infection strategies.

Arabidopsis ecotype Columbia-0 (Col-0) is known to be resistant to Alternaria brassicicola isolate MUCL 20297. Local and systemic defence-related gene expressions in Col-0 have been analysed to investigate molecular responses of an incompatible interaction (Schenk et al. 2003, Van Wees et al. 2003). Recently, disease susceptibility has been observed in another ecotype Dijon-G (Di-G) against the same isolate of Alternaria brassicicola, allowing comparative studies between compatible and incompatible interactions of Arabidopsis with necrotrophic fungus Alternaria brassicicola (Mukherjee et al. 2009). Different expressions of defence-related genes, such as pathogenesisrelated gene $(P R) 1$ and plant defensin $(P D F)$ 1.2, has been demonstrated in Col-0 and Di-G inoculated with the Alternaria brassicicola isolate (Mukherjee et al. 2009). Interestingly, Di-G has been known as an ecotype with an enhanced sensitivity to ethylene and selenite compared to Col-0 (Zhang et al. 2007, Chatfield and Raizada 2008). Gall formation in Arabidopsis root segments was much lower in Di-G infected with Agrobacterium tumefaciens compared to Col-0, which can be closely related to an extremely lower efficiency of Agrobacterium-mediated genetic transformation of Di-G than Col-0 (Nam et al. 1997, Clough and Bent, 1998). However, plant immunity to pathogens with different infection strategies in Di-G has not yet been deeply investigated yet.

The aim of this work was to demonstrate a different resistance of Col-0 and Di-G to oxalic acid (OA)producing necrotrophic fungi (Botrytis cinerea, Sclerotinia sclerotiorum, Sclerotium rolfsii), hemibiotrophic fungus (Colletotrichum higginsianum), and virus (TCV) infections based on symptom development and defence-related gene expression. Interrelation between an $\mathrm{OA}$ pathogenicity determinant and an SA defence regulator was also determined to understand behaviour of OA-producing necrotrophic fungal pathogens in Di-G.

\section{Materials and methods}

Plants, pathogens, and inoculation: Seeds of Arabidopsis thaliana L. ecotypes Col-0 and Di-G were purchased from the Arabidopsis Biological Resource Center according to The Arabidopsis Information Resource (TAIR) (https://www.arabidopsis.org/). For pathogen inoculations and chemical treatments, plants were grown in a growth chamber under a 12-h photoperiod, an irradiance of $120 \mu \mathrm{mol} \mathrm{m} \mathrm{m}^{-2} \mathrm{~s}^{-1}$, a temperature of $23 \pm 2{ }^{\circ} \mathrm{C}$ and a relative humidity of $75 \%$ for 6 weeks.

The grey mould disease-causing fungus Botrytis cinerea strain KACC 40573 was cultured on a $1 / 2$ potato dextrose agar (PDA) medium at a temperature of $25{ }^{\circ} \mathrm{C}$. A conidial suspension $\left(2 \times 10^{5}\right.$ conidia $\left.\mathrm{cm}^{-3}\right)$ was prepared in 1/4-strength potato dextrose broth, and then $7 \mathrm{~mm}^{3}$ of the conidial suspension was dropped on the centre of the adaxial surface of detached leaves. After fungal inoculation, whole plants or detached leaves were placed in a moist chamber with a relative humidity of $50 \%$, and disease symptoms developed at $20{ }^{\circ} \mathrm{C}$. Lesion diameters on $B$. cinerea-inoculated detached leaves were measured after 54 hours.

The Sclerotinia rot-causing fungus Sclerotinia sclerotiorum strain SRUi-1 isolated from a diseased watercress plant and the Sclerotium blight-causing fungus $S$. rolfsii strain KACC 40958 were cultured on 1/2-strength PDA media at $25{ }^{\circ} \mathrm{C}$. Mycelial agar discs $(3 \mathrm{~mm}$ in diameter) were excised from edges of newly growing fungal colonies and transferred onto detached leaves. These inoculated leaves were kept in a moist chamber with a relative humidity of $90 \%$, and relative lesion areas were determined.

The anthracnose fungus Colletotrichum higginsianum strain KACC 40807 was cultured on 1/2-strength PDA media at $25^{\circ} \mathrm{C}$, and its conidial suspension $\left(2 \times 10^{5}\right.$ conidia $\mathrm{cm}^{-3}$ ) was prepared in sterile distilled water. Detached leaves inoculated with the conidial suspension were kept in a moist chamber. The number of leaves showing spreading necrotic lesions with a chlorotic edge was counted among total inoculated leaves $(n=20)$ and expressed as a disease incidence percentage.

Transcripts were synthesised using T7 RNA polymerase (Promega, Madison, WI, USA) from a cloned cDNA of $T C V$ (pT7TCV66) and used for viral infection (Dempsey et al. 1997). These in vitro formed TCV transcripts were diluted in phosphate-buffered saline solution (PBS; 10 $\mathrm{mM} \mathrm{Na} \mathrm{HPO}_{4}, 2 \mathrm{mM} \mathrm{KH} \mathrm{PO}_{4}, 137 \mathrm{mM} \mathrm{NaCl}, \mathrm{pH}$ 7.4) containing Celite powder as a virus adsorbent and applied to 3 -week-old leaves using cotton swabs.

Oxalic acid and SA treatments: Different concentrations $(0,10,20,50$, and $100 \mathrm{mM})$ of OA solution were prepared in water and applied onto the leaf surface by dropping $7 \mathrm{~mm}^{3}$ of the solution at the centre. Lesion formation 
on detached leaves incubated in humid chambers was evaluated by measuring the lesion diameter after $60 \mathrm{~h}$ of incubation. For OA-inducible gene expression analysis, $2 \mathrm{mM}$ OA was sprayed onto plants. Water was sprayed on the plants of the same age as a mock treatment. The solution of SA $(0.5 \mathrm{mM})$ was prepared in water and sprayed onto the plants, and water was sprayed onto plants of the same age as a mock treatment. This concentration did not cause any visual symptom and was used to investigate the role of exogenous SA as a signal elicitor not as a stress molecule.

Salicylic acid measurement: Analytical conditions and internal standard preparation followed the method of Song et al. (2015). Briefly, leaf tissue (50 $\mathrm{mg}$ ) frozen in liquid nitrogen was ground and transferred to microtubes. Extraction solvent $\left(0.5 \mathrm{~cm}^{3}\right.$; 2-propanol : $\mathrm{H}_{2} \mathrm{O}$ : concentrated $\mathrm{HCl}, 2: 1: 0.002, \mathrm{v} / \mathrm{v} / \mathrm{v}$ ) was added to the leaf powder, and the microtubes were then placed at $4{ }^{\circ} \mathrm{C}$ with gentle shaking for $30 \mathrm{~min}$ (Pan et al. 2010). Then, $1 \mathrm{~cm}^{3}$ of dichloromethane was added, shaken for $30 \mathrm{~min}$, and centrifuged at $13000 \mathrm{~g}$ and $4{ }^{\circ} \mathrm{C}$ for $5 \mathrm{~min}$. Lower phases were recovered, dried, and dissolved in $0.1 \mathrm{~cm}^{3}$ of methanol. Total SA was quantified using an Agilent 1260 high performance liquid chromatography (HPLC) system (Agilent Technologies, Böblingen, Germany) coupled with an API 4000 mass spectrometry ( $A B$ SCIEX, Concord, Canada) equipped with a C18 column (Agilent Technologies) at $30{ }^{\circ} \mathrm{C}$. Chromatography conditions were as follows: $0.5 \mathrm{~min}, 95$ $5 \%$ mobile phase A $(0.1 \%, \mathrm{v} / \mathrm{v}$, formic acid in methanol) - mobile phase B (0.1\% formic acid, $\mathrm{v} / \mathrm{v}$, in water $) ; 1 \mathrm{~min}$, 5 - $95 \%$; 5 min, 5 - $95 \%$; $10 \mathrm{~s}, 95-5 \%$; 1 min return to initial conditions $95-5 \%$, at a flow rate of $0.5 \mathrm{~cm}^{3}$ $\mathrm{min}^{-1}$. Content of SA was calculated from the $\left[{ }^{2} \mathrm{H}_{4}\right]$-derived internal standard and expressed as $\mu \mathrm{g} \mathrm{g}^{-1}$ (f.m.).

Isolation of RNA and gene expression using reverse transcription semi-quantitative PCR: To examine gene expression in leaves, reverse transcription semi-quantitative PCR analysis was performed. Total RNA was isolated using RiboEx reagent (GeneAll Biotechnology Co., Seoul, the Republic of Korea) according to the manufacturer's instructions. First-strand cDNA was synthesized from $1 \mu \mathrm{g}$ of the total RNA with oligo $(d T)_{17}$ using SuperScript III reverse transcriptase (Invitrogen, Carlbad, USA). The resulting cDNA was used as a template with primer pairs shown in Table 1 Suppl. The PCR amplification was performed with an initial denaturation at $95{ }^{\circ} \mathrm{C}$ for 2 min followed by 23 to 30 cycles of $95{ }^{\circ} \mathrm{C}$ for $30 \mathrm{~s}, 52^{\circ} \mathrm{C}$ for $30 \mathrm{~s}$, and $72{ }^{\circ} \mathrm{C}$ for $30 \mathrm{~s}$ with a final extension step at $72{ }^{\circ} \mathrm{C}$ for $10 \mathrm{~min}$. Arabidopsis actin 2 gene expression was evaluated as an internal control. The PCR products were subjected to agarose gel electrophoresis, stained with RedSafe ${ }^{\mathrm{TM}}$ nucleotide acid staining solution (iNtRON Biotechnology, Seongnam, the Republic of Korea), and visualised by UV-radiation. At least three independent experiments were conducted for each gene expression analysis, and representative results were demonstrated in each figure.
Immunoblot for TCV accumulation: To verify TCV accumulation in Arabidopsis Col-0 and Di-G plants, total proteins were extracted from cauline leaves as previously described (Moon et al. 2016). Protein content in the extract was measured with a protein assay kit (Bio-Rad). The extract was separated by $10 \%(\mathrm{~m} / \mathrm{v})$ SDS-PAGE and transferred to a polyvinylidene difluoride membrane (Pierce, Biotechnology Inc., Rockford, IL, USA) using a wet-transfer apparatus (Mini Trans-Blot ${ }^{\circledR}$ cell, BioRad, Hercules, CA, USA). The membrane was probed with a polyclonal antiserum against recombinant TCV coat protein (CP) expressed in Escherichia coli (obtained from Dr. Dan Klessig) according to Kang et al. (2008). The TCV-CP was detected using an ECL plus reagent (GE Healthcare, Chicago, IL, USA) and visualised using an Alliance 9.7 chemiluminescence imaging system (UVITEC, Cambridge, UK).

\section{Results}

Detached leaves of Di-G were more susceptible to inoculation by three OA-producing necrotrophic fungi B. cinerea, S. sclerotiorum, and $S$. rolfsii according to enlarged lesions compared to those formed on Col-0 leaves (Fig. 1).

Treatments with OA at different concentrations resulted in a higher increase in lesion diameters in Di-G than in

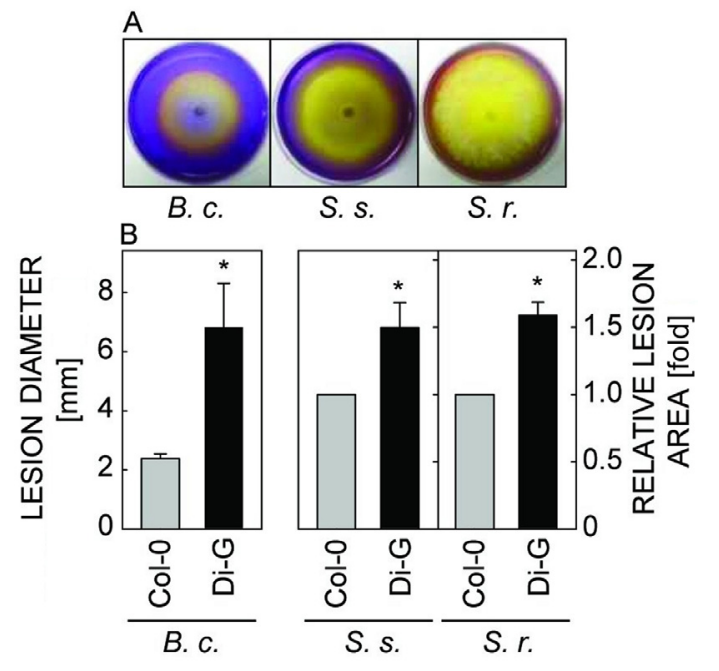

Fig. 1. Different responses of Arabidopsis ecotypes Col-0 and Di-G to oxalic acid (OA)-producing necrotrophic fungal pathogens Botrytis cinerea, Sclerotinia sclerotiorum, and Sclerotium rolfsii. A - Cultures of B. cinerea (B.c.), S. sclerotiorum (S.s.), and S. rolfsii (S.r.) on potato dextrose agar containing 0.01 $\%(\mathrm{~m} / \mathrm{v})$ bromophenol blue. Colour changes from blue violet to yellow indicates acidification of the media due to growing fungi secreting acidic compounds including OA. $B$ - Disease responses of Col-0 and Di-G measured as lesion diameters after $54 \mathrm{~h}$ and relative lesion areas (the areas of inoculated leaves of Di-G compared to those of Col-0 leaves). Means \pm SEs from four independent experiments. Asterisks indicate significant differences as determined by the Student's $t$-test $(P<0.05)$. 


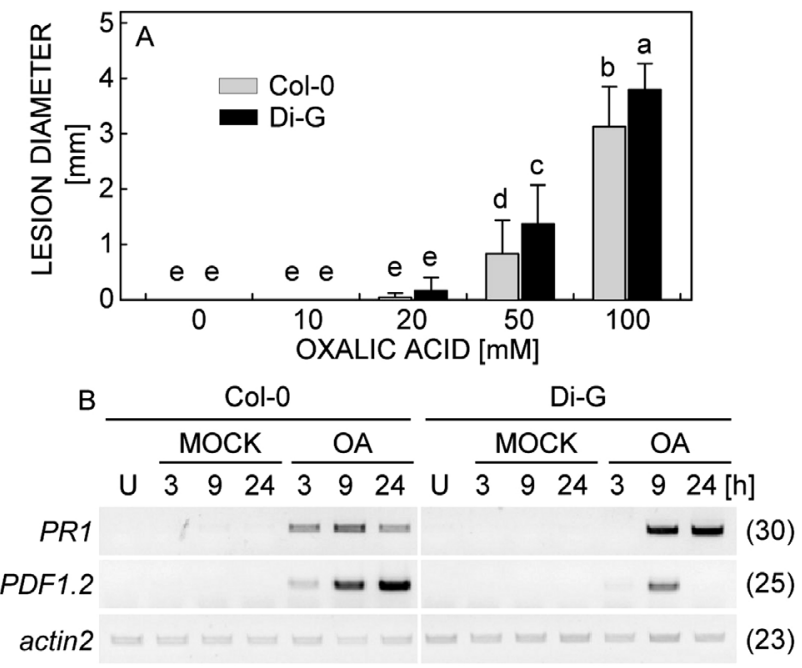

Fig. 2. Different responses of Arabidopsis ecotypes Col-0 and Di-G to oxalic acid (OA) treatments. $A$ - Enhanced susceptibility of $\mathrm{Di}-\mathrm{G}$ to exogenous OA demonstrated by necrotic lesion development on the leaves measured $60 \mathrm{~h}$ after OA treatments. Means \pm SEs from four independent experiments. Means with different letters were significantly different at $5 \%$ level as determined by the least significant difference (LSD) test. $B$ - Temporal transcriptional activation of defence-related genes $P R 1$ and PDF1.2 in leaf tissue of Col-0 and Di-G induced by OA treatment. Total RNA was isolated at indicated time points after mock or OA treatments (U - untreated). Gene expressions were determined by semi-quantitative reverse transcription PCR analysis, actin 2 was used as an internal control. The number of PCR cycles of each result is indicated on the right side in parentheses.

Col-0 (Fig. 2A). Less than $20 \mathrm{mM}$ of OA did not cause any significant symptom appearance on leaves of both the ecotypes, but significantly larger lesions were found in Di-G leaves treated with 50 and $100 \mathrm{mM} \mathrm{OA}$. Expressions of PR1 and PDF1.2 genes were differentially regulated in Col-0 and Di-G treated with 2 mM OA (Fig. $2 B$ ). The PR1 was slightly expressed in Col-0 within $3 \mathrm{~h}$ after OA treatment, and its expression remained high until $24 \mathrm{~h}$. However, no detectable $P R 1$ transcript was found in Di-G at $3 \mathrm{~h}$, and then a drastic increase of $P R 1$ gene expression was observed $9-24 \mathrm{~h}$ after OA treatment. The PDF1.2 expression was induced by OA in Col- 0 within $3 \mathrm{~h}$, and a gradual increase of $P D F 1.2$ transcript accumulation was found at 9 - $24 \mathrm{~h}$. However, a slight PDF1.2 expression occurred in Di-G treated with OA at $3 \mathrm{~h}$. It showed a moderate increase at $9 \mathrm{~h}$ and then a decrease at $24 \mathrm{~h}$.

Inoculation of Col-0 with $C$. higginsianum resulted in spreading necrotic lesions surrounded by chlorotic tissue whereas the lesion formation in Di-G was less established at 2 dpi (Figs. 3A). Disease incidence was increased in Col- 0 by the fungal infection at 3 dpi whereas a relatively low disease incidence was found in Di-G.

The $T C V$ infection resulted in different disease symptoms in Col-0 and Di-G (Fig. 3B). After 21 dpi, infected Col-0 displayed a severe growth retardation, crinkle and twisted yellow leaves, and only a few reproductive tissues compared to mock-inoculated plants. About $60 \%$ of $T C V$-inoculated Di-G plants did not show any symptom at $21 \mathrm{dpi}$ whereas $c a .40 \%$ of Di-G showed symptoms similar to $T C V$-infected Col-0. In a $T C V$ resistant ecotype Di-17 (Park and Klessig, 2003), all TCVinoculated Di-17 plants remain symptomless at $21 \mathrm{dpi}$. To determine whether the resistant phenotype of Di-G plants might be caused by a reduced virus accumulation,
TCV coat proteins accumulated in Col- 0 and Di-G were monitored by an immunoblot analysis. High amounts of TCV-CP were observed at $21 \mathrm{dpi}$ in Col-0 plants and susceptible Di-G plants, which shows severe symptoms of $T C V$ infection whilst accumulation of TCV CP was absent in resistant Di-G plants, which did not show any symptoms.

To investigate molecular responses of Col-0 and Di-G ecotypes to defence hormone SA, accumulation of endogenous SA and expressions of PRI and PDF1.2 genes were analysed (Fig. 4). Application of $0.5 \mathrm{mM}$ SA increased content of SA in leaf tissue of Col-0 and Di-G differently (Fig. 4A). Total SA content in Col-0 and Di-G leaves without any treatment was not significantly different. Content of SA in Col-0 leaves remained stable at 3 and $9 \mathrm{~h}$ after mock treatment but slightly reduced after $24 \mathrm{~h}$. Exogenous SA increased content of endogenous SA in Col-0 leaves $c a$. 1.9-times $3 \mathrm{~h}$ after treatment and $c a$. 2.3-times after $9 \mathrm{~h}$. After $24 \mathrm{~h}$, SA content was slightly reduced to $c a$. 1.7-times. In Di-G mock-treated, SA content decreased slightly after 3 - $24 \mathrm{~h}$. A higher SA content was found in Di-G compared to Col-0 at each time point after application of SA. Increases of SA content in Di-G leaves after SA treatments were $c a$. 2.4-, 2.8-, and 2.0-times after 3,9 , and $24 \mathrm{~h}$, respectively.

The PRI was induced in Col- 0 by $0.5 \mathrm{mM}$ of SA 3 - $24 \mathrm{~h}$ after treatment (Fig. $4 B$ ). A gradual increase of SA-induced $P R 1$ expression was also found in Di-G with a similar time course although transcript accumulation was higher in comparison with Col-0 at each time point. The PDF 1.2 was not inducible by SA in both the ecotypes. No distinct differences in the expressions of genes enhanced disease susceptibility (EDS) 1 or nonexpresser of PR genes (NPR) 1 encoding ankyrin-repeats transcription factor 1 

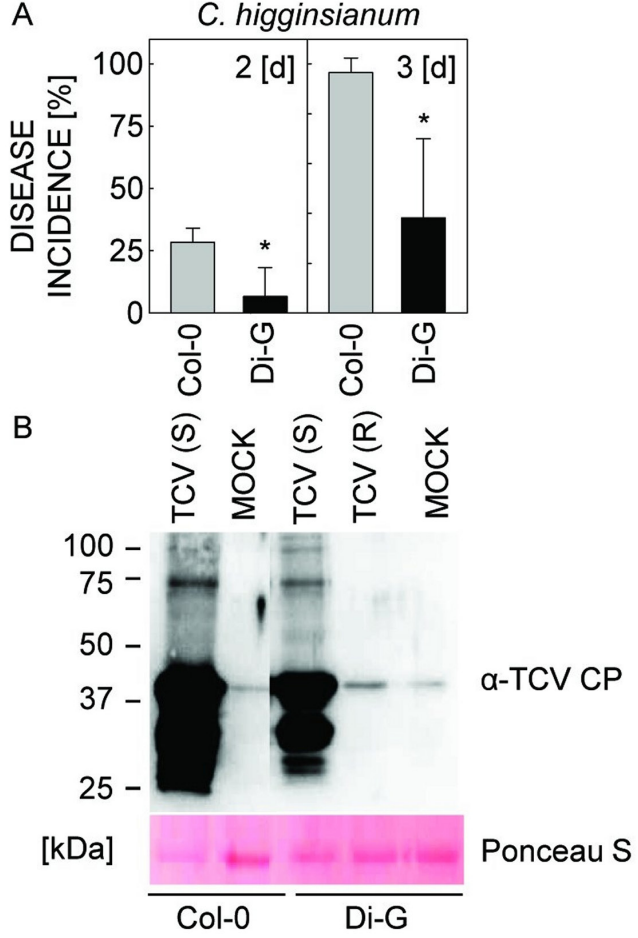

Fig. 3. The responses of Arabidopsis ecotypes Col-0 and Di-G to hemibiotrophic fungus Colletotrichum higginsianum and biotrophic Turnip crinkle virus infections. $A$ - Disease response of Col-0 and Di-G to inoculation with conidial suspension (2 $\times 10^{5}$ conidia $\mathrm{cm}^{-3}$ ) of $C$. higginsianum observed at $2-3$ dpi. Means \pm SEs, $n=20$. Asterisks indicate significant differences as determined by the Student's $t$-test $(P<0.05)$. $B$ - Turnip crinkle virus (TCV) disease symptoms in Col- 0 and Di-G plants. Threeweek-old plants were inoculated with $T C V$ or buffer (mock). The $T C V$ infection was detected in resistant (R) and susceptible (S) plants at $21 \mathrm{dpi}$. Immunoblot analysis was performed to measure TCV coat protein $(\mathrm{CP})$ accumulation in cauline leaves. In each lane, $10 \mu \mathrm{g}$ of total protein was loaded. The blot was probed with an anti-TCV CP antibody. Ponseau S staining was performed to verify equal loading proteins.

were found between Col-0 and Di-G after SA treatment. However, transiently higher expressions of EDS5, EDS16, and phytoalexin deficient (PAD) 4 genes were induced by $\mathrm{SA}$ application at $9 \mathrm{~h}$ in Di-G leaves compared to those in Col-0 leaves.

The role of SA signalling in OA-triggered plant cell death was demonstrated in both the ecotypes (Fig. 5). The Col-0 and Di-G pre-treated with SA showed differential responses: SA did not change the lesion diameter in Col-0, however, Di-G was more vulnerable to OA due to SA pre-treatment (Fig. 5A). OA-induced PRI gene expression slightly increased by SA pre-treatment in Col-0 and Di-G whereas OA-induced PDF1.2 gene expression was profoundly compromised by SA pre-treatment in both the ecotypes. Decreased OA-induced PDF1.2 gene expression was more distinct in Di-G than that in Col-0 plants (Fig. 5B).

\section{Discussion}

The Arabidopsis ecotype Di-G is susceptible to $B$. cinerea, $S$. sclerotiorum, and $S$. rolfsii infections as well as $A$. brassicicola suggesting that an enhanced disease susceptibility of Di-G might be to a broad spectrum of necrotrophic fungal invasions. The resistance of Col-0 to $S$. sclerotiorum has been reported to be dependent on SA, JA, and ethylene signalling (Guo and Stotz 2007). An increased Sclerotinia rot symptom in Di-G leaves might be caused by reduced or defective defence signalling mediated by SA, JA, and/or ethylene. However, the resistance of Di-G against $S$. sclerotiorum infection might be highly dependent on JA and/or ethylene but not on SA signalling. The Di-G might have a high content of SA or SA-signalling activation system against an OA-producing necrotrophic fungal invasion. Highly activated SA-related defences may attenuate JA/ethylene-mediated defence, by which resistance to necrotrophic fungi can be declined in Di-G. Interestingly, OA produced by $B$. cinerea, S. sclerotiorum, and $S$. rolfsii during pathogenesis has been known as one of critical pathogenicity factors to stimulate host cell death (Lehner et al. 2008). An enhanced susceptibility of Di-G against these three OA-generating fungal infections could be associated with a higher sensitivity of Di-G to OA secreted from these fungi, at least in part.

These two ecotypes showed completely different responses to the hemibiotrophic pathogen $C$. higginsianum employing an initial symptomless biotrophic and subsequent destructive necrotrophic colonisation. The resistance of an ecotype Eil-0 to $C$. higginsianum is negatively correlated with activation of JA/ethylene defence signalling, a low antifungal camalexin production, and low expressions of PR4 and PDF1.2 in response to fungal attack (Narusaka et al. 2004). There are quite different from responses of Col-0. The resistance of Eil-0 is rather associated with a hypersensitive cell death at fungal penetrated sites. Differential responses of Col- 0 and Di-G to $A$. brassicicola and C. higginsianum infections might be due to differential activation of defence signalling pathways against these fungal pathogens with necrotrophic and hemibiotrophic infection strategies (Glazebrook 2005). Necrotrophic A. brassicicola led to attenuated activation of JA and/or ethylene signalling in Di-G whereas hemibiotrophic $C$. higginsianum mediated augmented SA-dependent pathways leading to an enhanced disease resistance. An inefficient activation of camalexin production and JA/ethylene defence signalling might lead to an enhanced susceptibility to $A$. brassicicola. However, they confer resistance to $C$. higginsianum in DiG. Surprisingly, disease resistances of Col-0 and Di-G to $B$. cinerea and $C$. higginsianum were unlike in previous studies (Narusaka et al. 2004, 2013), which is different from our current results. Such discrepancy might be due to differences in pathogen genotypes, plant growth stages, and/or inoculation methods of the present study (Denby et al. 2004, Liu et al. 2007, 2017). The enhanced susceptibility of the ecotype Di-G to $B$. cinerea and its resistance to $C$. higginsianum remains to be elucidated by using various fungal isolates and environmental conditions. 


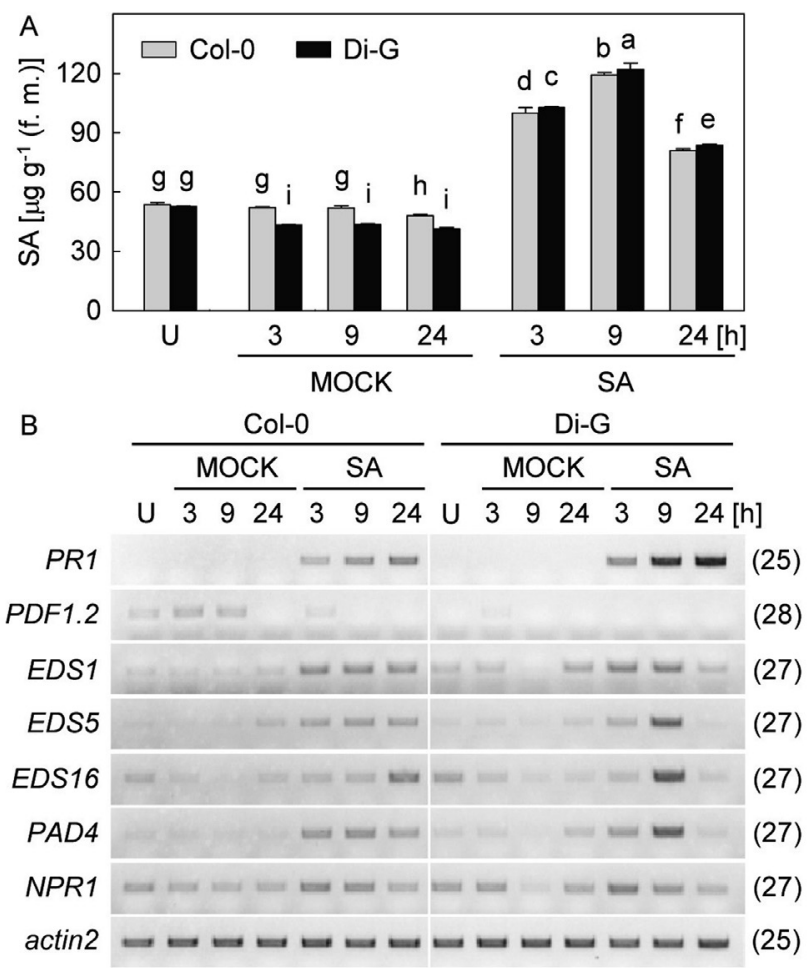

Fig. 4. Salicylic acid (SA)-mediated defence signalling in Arabidopsis ecotypes Col-0 and Di-G. A - Accumulation of endogenous SA in different time points in response to application of $0.5 \mathrm{mM} \mathrm{SA}$ (U - untreated). Means \pm SEs from four independent experiments. Means with different letters were significantly different at $5 \%$ level as determined by the least significant difference (LSD) test. $B$ Transcriptional activation of defence-related genes by SA treatment. Total RNA was isolated at indicated time points after mock or SA treatments. Gene expressions were determined by semi-quantitative reverse transcription PCR analysis, and actin 2 was used as a control. The number of PCR cycles of each result is indicated on the right side in parentheses.

A

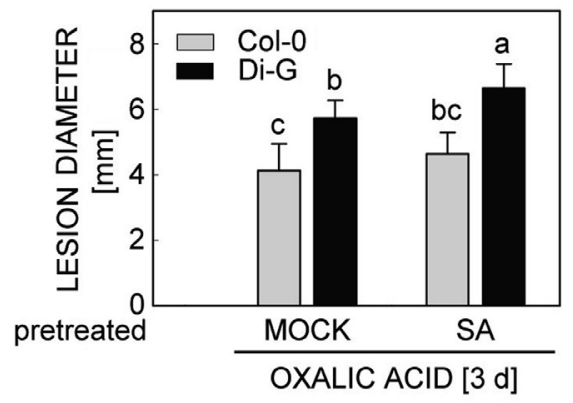

B
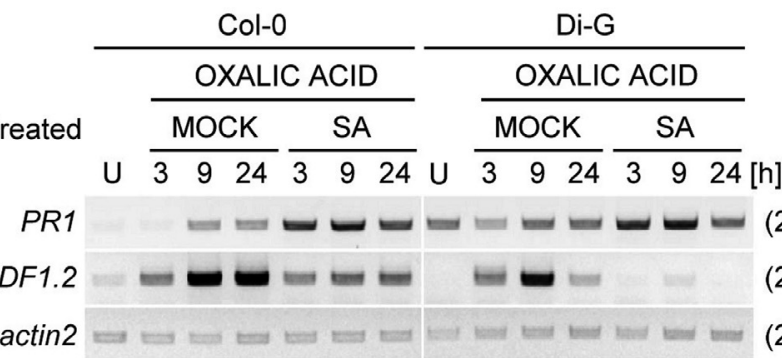

Fig. 5. Interactions between oxalic acid (OA) and salicylic acid (SA) in Arabidopsis ecotypes Col-0 and Di-G. $A$ - A 2 mM OA-triggered lesion formation on detached leaves of the two ecotypes with or without $0.5 \mathrm{mM}$ SA pre-treatment. Data are presented as mean lesion diameters \pm SEs from four independent experiments. Means with different letters are significantly different at $5 \%$ level as determined by the least significant difference (LSD) test. $B$ - Transcriptional activation of defence-related genes $P R I$ and $P D F 1.2$ in leaf tissue during SA-OA interaction. Mock and $0.5 \mathrm{mM} \mathrm{SA}$ were used $24 \mathrm{~h}$ prior to $2 \mathrm{mM}$ OA application. Total RNA was isolated at indicated time points after OA treatment (U - untreated). Gene expressions were determined by semi-quantitative reverse transcription PCR analysis, and actin2 was used as a control. The number of PCR cycles of each result is indicated on the right side in parentheses. 
Biotrophic pathogens, such as $T C V$, can trigger SA-dependent signalling pathways in Col-0 (Kachroo et al. 2000, Chandra-Shekara et al. 2004). Salicylic acid and JA/ethylene signalling pathways are antagonistic during defence cascade reactions against pathogens of different lifestyles of Arabidopsis (Leon-Reyes et al. 2010). Application of SA resulted in a higher endogenous SA content and SA-related gene expressions in Di-G suggesting that invading pathogens mainly triggering SA defence pathways in host plants might highly increase disease resistance of Di-G. Whether SA-dependent defence responses are more activated in Di-G than in Col-0 by hemibiotrophic and biotrophic fungal invasions as well as viral infection needs to be further elucidated.

Early defence signalling components EDS1, EDS5, EDS16, PAD4, and NPR1 contributed to the establishment of SA-mediated defence activation (Nawrath et al. 2002). The EDS1, EDS5 and PAD4 can be transcriptionally regulated in Col-0 by SA (Falk et al. 1999, Jirage et al. 1999, Nawrath et al. 2002). The Di-G has developed more sensitive molecular machineries in response to SAtriggered stimuli compared to Col-0. It was evidenced by more transcripts of EDS1, EDS5, and PAD4 accumulated in Di-G after SA application although they were transiently expressed. It may lead to a distinct $P R I$ gene expression in the downstream signalling pathways. Interestingly, no altered response was found in eds 5 or pad4 mutants indicating that these genes might not be related to disease resistance to $B$. cinerea infection (Ferrari et al. 2003). However, mutations in EDS5 and PAD4 genes restore suppressor of SA insensitivity 2 (ssi2)-mediated enhanced susceptibility to $B$. cinerea (Nandi et al. 2005). Mutations in EDS5, EDS16 and PAD4 genes in Di-G background will unravel functional roles of SA-inducible expressions of these genes during the enhanced disease susceptibility to necrotrophic fungi. The EDS1 or NPR1 did not seem to be involved in regulation of $P R 1$ gene expression, which was quite different in Col-0 and Di-G ecotypes. A high responsiveness to SA-triggered signalling in Di-G may enhance the resistance to $C$. higginsianum and $T C V$ whereas Di-G showed a lowered resistance to necrotrophs $B$. cinerea, $S$. sclerotiorum, and $S$. rolfsii via suppression of JA/ethylene-mediated defences.

In conclusion, Arabidopsis Di-G showed different disease responses to various pathogens with different infection strategies compared to Col-0. It may be closely related to altered SA- and JA/ethylene-associated signalling in Di-G. Comparatively dissecting defence pathways of Col-0 and Di-G via molecular and genetic tools will provide more profound insights into differential disease resistance to necrotrophic and biotrophic pathogens.

\section{References}

Ahmad, S., Van Hulten, M., Martin, J., Pieterse, C.M.J., Van Wees, S.C.M., Ton, J.: Genetic dissection of basal defence responsiveness in accessions of Arabidopsis thaliana. - Plant Cell Environ. 34: 1191-1206, 2011.

Bouchabke, O., Chang, F., Simon, M., Voisin, R., Pelletier, G., Durand-Tardif, M.: Natural variation in Arabidopsis thaliana as a tool for highlighting differential drought responses. PLoS ONE 3: e1705, 2008.

Brosché, M., Merilo, E., Mayer, F., Pechter, P., Puzõrjova, I., Brader, G., Kangasjärvi, J., Kollist, H.: Natural variation in ozone sensitivity among Arabidopsis thaliana accessions and its relation to stomatal conductance. - Plant Cell Environ. 33: 914-925, 2010

Chandra-Shekara, A.C., Navarre, D., Kachroo, A., Kang, H.-G., Klessig, D., Kachroo, P.: Signaling requirements and role of salicylic acid in HRT- and rrt-mediated resistance to turnip crinkle virus in Arabidopsis. - Plant J. 40: 647-659, 2004

Chatfield, S.P., Raizada, M.N.: Ethylene and shoot regeneration: hookless 1 modulates de novo shoot organogenesis in Arabidopsis thaliana. - Plant Cell Rep. 27: 655-666, 2008.

Clough, S.J., Bent, A.F.: Floral dip: a simplified method for Agrobacterium-mediated transformation of Arabidopsis thaliana. - Plant J. 16: 735-743, 1998.

Dempsey, D.A., Pathirana, M.S., Wobbe, K.K., Klessig, D.F.: Identification of an Arabidopsis locus required for resistance to turnip crinkle virus. - Plant J. 11: 301-311, 1997.

Denby, K.J., Kumar, P., Kliebenstein, D.J.: Identification of Botrytis cinerea susceptibility loci in Arabidopsis thaliana. Plant J. 38: 473-486, 2004.

Falk, A., Feys, B.J., Frost, L.N., Jones, J.D.G., Daniels, M.J., Parker, J.E.: EDS1, an essential component of $R$ genemediated disease resistance in Arabidopsis has homology to eukaryotic lipases. - Proc. nat. Acad. Sci. USA 96: 3292$3297,1999$.

Ferrari, S., Plotnikova, J.M., De Lorenzo, G., Ausubel, F.M.: Arabidopsis local resistance to Botrytis cinerea involves salicylic acid and camalexin and requires EDS4 and PAD2, but not SID2, EDS5 or PAD4. - Plant J. 35: 193-205, 2003.

Glazebrook, J.: Contrasting mechanisms of defense against biotrophic and necrotrophic pathogens. - Annu. Rev. Phytopathol. 43: 205-227, 2005.

Guo, X., Stotz, H.U.: Defense against Sclerotinia sclerotiorum in Arabidopsis is dependent on jasmonic acid, salicylic acid, and ethylene signaling. - Mol. Plant-Microbe Interact. 20: 13841395, 2007.

Hannah, M.A., Wiese, D., Freund, S., Fiehn, O., Heyer, A.G., Hincha, D.K.: Natural genetic variation of freezing tolerance in Arabidopsis. - Plant Physiol. 142: 98-112, 2006.

Jirage, D., Tootle, T.L., Reuber, T.L., Frost, L.N., Feys, B.J., Parker, J.E., Ausubel, F.M., Glazebrook, J.: Arabidopsis thaliana PAD4 encodes a lipase-like gene that is important for salicylic acid signaling. - Proc. nat. Acad. Sci. USA 96: 13583-13588, 1999.

Kachroo, P., Yoshioka, K., Shah, J., Dooner, H.K., Klessig, D.F.: Resistance to turnip mosaic virus in Arabidopsis is required by two host genes and is salicylic acid dependent but not NPR1, ethylene, and jasmonate independent. - Plant Cell 12: 677-690, 2000.

Kang, H.G., Kuhl, J.C., Kachroo, P., Klessig, D.F.: CRT1, an Arabidopsis ATPase that interacts with diverse resistance proteins and modulates disease resistance to Turnip Crinkle Virus. - Cell Host Microbe 3: 48-57, 2008.

Kover, P.X., Schaal, B.A.: Genetic variation for disease resistance and tolerance among Arabidopsis thaliana accessions. - Proc. nat. Acad. Sci. USA 99: 11270-11274, 2002.

Lehner, A., Meimoun, P., Errakhi, R., Madiona, K., Barakate, M., Bouteau, F.: Toxic and signalling effects of oxalic acid. - Plant Signal Behav. 3: 746-748. 2008.

Leisner, S.M., Howell, S.H.: Symptom variation in different Arabidopsis thaliana ecotypes produced by cauliflower mosaic virus. - Phytopathology 82: 1042-1046, 1992.

Lempe, J., Balasubramanian, S., Sureshkumar, S., Singh, A., 
Schmid, M., Weigel, D.: Diversity of flowering responses in wild Arabidopsis thaliana strains. - PLoS Genetics 1: e6, 2005.

Leon-Reyes, A., Van der Does, D., De Lange, E.S., Delker, C., Wasternack, C., Van Wees, S. C.M., Ritsema, T., Pieterse, C.M.J.: Salicylate-mediated suppression of jasmonateresponsive gene expression in Arabidopsis is targeted downstream of the jasmonate biosynthesis pathway. - Planta 232:1423-1432, 2010.

Leon-Reyes, A., Du, Y., Koornneef, A., Proietti, S., Körbes, A.P., Memelink, J., Pieterse, C.M.J., Ritsema, T.: Ethylene signaling renders the jasmonate response of Arabidopsis insensitive to future suppression by salicylic acid. - Mol. Plant-Microbe Interact. 23: 187-197, 2010.

Liu, G., Kennedy, R., Greenshields, D.L., Peng, G., Forseille, L., Selvaraj, G., Wei, Y.: Detached and attached Arabidopsis leaf assays reveal distinct defense responses against hemibiotrophic Colletotrichum spp. - Mol. Plant-Microbe Interact. 20: 1308-1319, 2007.

Liu, S., Ziegler, J., Zeier, J., Birkenbihl, R.P., Somssich, I.E.: Botrytis cinerea B05.10 promotes disease development in Arabidopsis by suppressing WRKY33-mediated host immunity. - Plant Cell Environ. 40: 2189-2206, 2017.

Mang, H.G., Laluk, K.A., Parsons, E.P., Kosma, D.K., Cooper, B.R., Park, H.C., AbuQamar, S., Boccongelli, C., Miyazaki, S., Consiglio, F., Chilosi, G., Bohnert, H.J., Bressan, R.A., Mengiste, T., Jenks, M.A.: The Arabidopsis RESURRECTION1 gene regulates a novel antagonistic interaction in plant defense to biotrophs and necrotrophs. Plant Physiol. 151: 290-305, 2009.

Martín, A.M., Cabrera y Poch, H.L., Martínez Herrera, D., Ponz, F.: Resistance to turnip mosaic potyvirus in Arabidopsis thaliana. - Mol. Plant-Microbe Interact. 12: 1016-1021, 1999.

Martín, A.M., Martínez Herrera, D., Poch y Cabrera, H.L., Ponz, F.: Variability in the interactions between Arabidopsis thaliana ecotypes and oilseed rape mosaic tobamovirus. Aust. J. Plant Physiol. 24: 275-281, 1997.

Matthes, M.C., Pickett, J.A., Napier, J.A.: Natural variation in responsiveness of Arabidopsis thaliana to methyl jasmonate is developmentally regulated. - Planta 228: 1021-1028, 2008.

Moon, J.Y., Lee, J.H., Oh, C.S., Kang, H,G., Park, J.M.: Endoplasmic reticulum stress responses function in the HRTmediated hypersensitive response in Nicotiana benthamiana. - Mol. Plant Pathol. 17: 1382-1397, 2016.

Mukherjee, A.K., Lev, S., Gepstein, S., Horwitz, B.A.: A compatible interaction of Alternaria brassicicola with Arabidopsis thaliana ecotype DiG: evidence for a specific transcriptional signature. - BMC Plant Biol. 9: 31. 2009.

Nandi, A., Moeder, W., Kacchroo, P., Klessig, D.F., Shah, J.: Arabidopsis ssi2-conferred susceptibility to Botrytis cinerea is dependent on EDS5 and PAD4. - Mol. Plant-Microbe Interact. 18:363-370, 2005.

Nam, J., Mattysse, A.G., Gelvin, S.B.: Differences in susceptibility of Arabidopsis ecotypes to crown gall disease may result from a deficiency in T-DNA integration. - Plant Cell 9: 317-333, 1997.

Narusaka, M., Yao, N., Iuchi, A., Iuchi, S., Shiraishi, T., Narusaka, Y.: Identification of Arabidopsis thaliana accession with resistance to Botrytis cinerea by natural variation analysis, and characterization of the resistance response. Plant Biotechnol. 30: 89-95, 2013.
Narusaka, Y., Narusaka, M., Park, P., Kubo, Y., Hirayama, T., Seki, M., Shiraishi, T., Ishida, J., Nakashima, M., Enju, A., Sakurai, T., Satou, M., Kobayashi, M., Shinozaki, K.: RCH1, a locus in Arabidopsis that confers resistance to the hemibiotrophic fungal pathogen Colletotrichum higginsianum. - Mol. PlantMicrobe Interact. 17: 749-762, 2004.

Nawrath, C., Heck, S., Parinthawong, N., Métraux, J.-P.: EDS5, an essential component of salicylic acid-dependent signaling for disease resistance in Arabidopsis, is a member of the MATE transporter family. - Plant Cell 14: 275-286, 2002.

Nawrath, C., Métraux, J.-P.: Salicylic acid induction-deficient mutants of Arabidopsis express $P R-2$ and $P R-5$ and accumulate high levels of camalexin after pathogen inoculation. - Plant Cell 11: 1393-1404, 1999.

Pan, X., Welti, R., Wang, X.: Quantitative analysis of major plant hormones in crude plant extracts by high-performance liquid chromatography-mass spectrometry. - Nat. Protocol 5: 986992, 2010.

Park, J.M., Klessig, D.F.: HRT-mediated Turnip crinkle virus resistance in Arabidopsis. - Plant Pathol. J. 19: 19-23, 2003.

Perchepied, L., Kroj, T., Tronchet, M., Loudet, O., Roby, D.: Natural variation in partial resistance to Pseudomonas syringae is controlled by two major QTLs in Arabidopsis thaliana. - PLoS ONE 1: e123, 2006.

Pieterse, C.M.J., Leon-Reyes, A., Van der Ent, S., Van Wees, S.C.M.: Networking by small-molecule hormones in plant immunity. - Natur. chem. Biol. 5: 308-316, 2009.

Rowe, H.C., Kliebenstein, D.J.: Complex genetic control natural variation in Arabidopsis thaliana resistance to Botrytis cinerea. - Genetics 180: 2237-2250, 2008.

Schenk, P.M., Kazan, K., Manners, J.M., Anderson, J.P., Simpson, R.S., Wilson, I.W., Somerville, S.C., Maclean, D.J.: Systemic gene expression in Arabidopsis during an incompatible interaction with Alternaria brassicicola. - Plant Physiol. 132: 999-1010, 2003.

Song, G.C., Lee, S., Hong, J., Choi, H.K., Hong, G.H., Bae, D.W., Mysore, K.S., Park, Y.-S., Ryu, C.-M.: Aboveground insect infestation attenuates belowground Agrobacterium-mediated genetic transformation. - New Phytol. 207: 148-158, 2015.

Spoel, S.H., Johnson, J.S., Dong, X.: Regulation of trade offs between plant defenses against pathogens with different lifestyles. - Proc. nat. Acad. Sci. USA 104: 18842-18847, 2007.

Van Leeuwen, H., Kliebenstein, D.J., West, M.A.L., Kim, K., Van Poecke, R., Katagiri, F., Michelmore, R.W., Doerge, R.W., St. Clair, D.A.: Natural variation among Arabidopsis thaliana accessions for transcriptome response to exogenous salicylic acid. - Plant Cell 19: 2099-2110, 2007.

Van Wees, S.C.M., Chang, H.S., Zhu, T., Glazebrook, J.: Characterization of the early response of Arabidopsis to Alternaria brassicicola infection using expression profiling. - Plant Physiol. 132: 606-617, 2003.

Xiao, S., Calis, O., Patrick, E., Zhang, G., Charoenwattana, P., Muskett, P., Parker, J.E., Turner, J.G.: The atypical resistance gene, $R P W 8$, recruits components of basal defence for powdery mildew resistance in Arabidopsis. - Plant J. 42: 95110, 2005.

Zhang, L., Ackley, A.R., Pilon-Smits, E.A.H.: Variation in selenium tolerance and accumulation among 19 Arabidopsis thaliana accessions. - J. Plant Physiol. 164: 327-336, 2007. 